\title{
Relações objetais na primeira infância e a construção do reconhecimento recíproco na teoria de Axel Honneth.
}

\author{
Mario Jorge Fonseca Junior' ${ }^{\text {; }}$ Carlos César Barros ${ }^{2}$ \\ 1.Bolsista PIBIC/CNPq, Graduando em Psicologia, Universidade Estadual de Feira de Santana, e-mail: \\ mariouefs@gmail.com \\ 2.Orientador, Departamento de Ciências Humanas e Filosofia, Universidade Estadual de Feira de Santana, e-mail: \\ carlosbarros@uefs.br
}

PALAVRAS CHAVE: reconhecimento; René Spitz; Axel Honneth.

\section{INTRODUÇÃO}

Oriundo do projeto "Psicologia e reconhecimento dos direitos humanos: categorias psicológicas na teoria do reconhecimento de Axel Honneth", a partir de discussões realizadas na tese de livre-docência "A luta pelo reconhecimento: a gramática moral dos conflitos sociais" (Honneth, 2003), do atual diretor do Instituto de Pesquisa Social da Escola de Frankfurt, Axel Honneth, a pesquisa tem como tema as relações afetivas primárias e sua importância no processo de reconhecimento recíproco. Fundamentado nas construções teóricas de Hegel e nas investigações empíricas do pragmatista Mead, Honneth (2003) rediscute de forma coesa as relações humanas em suas dimensões individual e intersubjetiva, ou seja, consigo mesmo e nas relações sociais, as quais estão relacionadas com as três esferas de interação: o afeto, que nutre a autoestima a partir das relações com os cuidadores; a jurídica, vinculada ao autorrespeito e às normas sociais; a solidariedade, atrelada às relações com os grupos sociais. $\mathrm{Na}$ dimensão do afeto, ou amor, primeira etapa para estabelecer o reconhecimento afetivo, Honneth (2003) ressalta as relações primárias do bebê e a formação de identidade nesta primeira fase.

A leitura da obra La sociedad del desprecio (Honneth, 2011) evidencia em seu sexto capítulo, Teoría de la relación de objeto e identidad posmoderna: sobre el supuesto envejecimiento del psicoanálisis, o surgimento das teorias que vislumbram o sujeito como um ser múltiplo no seu desenvolvimento psíquico. As pesquisas sócio-psicológicas contribuíram com essa nova visão do ser humano, ampliando a concepção freudiana, para a qual o sujeito constrói a sua identidade pessoal a partir do investimento libidinal no outro cuidador, para uma abordagem em que o indivíduo forma o seu psiquismo a partir das relações estabelecidas na sociedade em diversas dimensões de interação, configurando processos de pluralização intrapsíquica dos sujeitos.

Dentre os teóricos da psicanálise das relações de objeto, Honneth (2003) destaca a análise do primeiro ano de vida realizada por René Spitz, teórico da psicologia do desenvolvimento, considerado um dos primeiros a fazer uma investigação da Psicologia Infantil, e a desenvolver conteúdos sobre a construção do ego nesta fase em seu livro " $O$ primeiro ano de vida" (Spitz, 2013). Honneth (2003) aborda os resultados das investigações de Sptiz, afirmando que as pesquisas trouxeram "provas convincentes para o fato de que a interação entre mãe e criança se efetua como um processo altamente complexo, no qual ambos os implicados se exercitam mutuamente na capacidade de vivenciar em comum sentimentos e percepções (Honneth, 2003, p. 162). Com isso, delimitamos a temática e problemática desta pesquisa na análise e compreensão do papel das relações mãe-filho no desenvolvimento do bebê (Spitz, 2013) como modelo para ilustrar a dimensão afetiva da luta por reconhecimento, destacando as origens da percepção a partir das relações mãe-filho e da comunicação humana

\section{METODOLOGIA}


A pesquisa teve como base o livro O primeiro ano de vida (Spitz, 2013), no qual o autor apresenta as origens da percepção, das relações mãe-filho e da comunicação humana. $O$ estudo de Spitz foi sempre referenciado pelo raciocínio psicossociológico apresentado em "Luta por Reconhecimento: a Gramática Moral dos Conflitos Sociais" (Honneth, 2003), obra em que o autor aborda os estudos das primeiras relações afetivas na construção da identidade e do reconhecimento recíproco.

A obra La sociedad del desprecio (Honneth, 2011) rediscute a concepção das relações de objeto freudiana, conteúdo que compõe a teoria do desenvolvimento de Spitz (2013). Dialogando com Mead, Spitz (2013) faz referência ao psicólogo social pragmatista, utilizando sua obra Mente, self e sociedade (Morris, 2010) para sua teoria da comunicação.

Ainda como base de apoio para as leituras, tivemos a atividade semanal do grupo de estudos sobre as categorias psicológicas na teoria do reconhecimento de Axel Honneth, coordenado pelo Professor Carlos Barros, do qual participaram outros pesquisadores que estudaram temas relacionados.

Por se tratar de uma pesquisa baseada essencialmente em investigação bibliográfica, o presente trabalho foi orientado pela metodologia científica desenvolvida por Marconi e Lakatos (2006), com as seguintes etapas de produção: identificação da bibliografia em catálogos de editoras, bibliotecas e periódicos na Internet, análise de resumos e bibliografias das obras encontradas; localização das obras relevantes para a pesquisa; compilação; fichamento; análise e interpretação das mesmas.

\section{RESULTADOS}

Em Spitz, nos primeiros meses de vida, a criança não diferencia o id e o ego, o consciente e o inconsciente que, posteriormente, irão se separar. Acredita também que há a não diferenciação das regiões corporais, as quais ainda não estão no campo da percepção. A falta de organização está nas dimensões psicológicas e fisiológicas, exceto nas áreas indispensáveis para a sobrevivência.

Ao nascer, o sujeito possui uma proteção do aparelho perceptivo, cuja função é bloquear as estimulações externas e evitar as sensações desprazerosas. Porém, esta barreira precisa de auxílios externos e internos para efetivar suas funções, sendo o auxílio da mãe crucial. A mãe, ao proteger o bebê de diversos estímulos externos, evita a sobrecarga; a assistência aos estímulos internos que a mãe oferta, por exemplo, à fome, faz com que a alimentação descarregue a tensão do bebê. Enquanto a mãe alimenta o bebê, ela estabelece uma comunicação ou "diálogo". Esta sequência cria um mundo exclusivo para o bebê, um clima emocional específico (Spitz, 2013). É o diálogo que dará significado aos estímulos por meio de um processo gradual.

Pra esse contexto, os cuidados que visam à sobrevivência e os sentimentos da mãe em relação ao filho são de grande importância. Segundo Spitz, esses sentimentos variam de mãe para mãe. Essa interação dual produz um clima emocional favorável ao desenvolvimento da criança (Spitz, 2013).

São os sentimentos maternos em relação ao filho que criam esse clima emocional. $\mathrm{O}$ amor e afeição pelo filho o tornam um objeto de contínuo interesse para a mãe; e além desse interesse persistente ela lhe oferece uma gama sempre renovada, rica e variada, todo um mundo, de experiências vitais (Spitz, 2013, p. 100).

Para além da interação, Spitz denominou os fatores que promovem a transição dos estágios para o desenvolvimento humano de "organizadores" da psique. Tais fatores são importantes e constituem o processo de estabelecimento do objeto de amor e o reconhecimento do outro enquanto sujeito autônomo; saída do estado de desamparo da criança e da dependência mútua mãe-filho. 
O estágio pré-objetal marca o surgimento do primeiro organizador da psique, surgimento que ocorre aos três meses de idade. Na primeira experiência, o ego está limitado à percepção, reconhecimento e reação Gestalt-sinal de satisfação da necessidade. O ego não consegue diferir-se dos objetos que estão interagindo com a criança. A sua operação só ocorre por causa dos auxílios maternos (ego auxiliar). Nesse período, o ego é rudimentar e não possui uma estrutura inteligente.

Aos oito meses de vida há um novo marco no desenvolvimento do sujeito: os rostos desconhecidos são rejeitados no processo de confrontar os traços de memória materna com os estranhos que se aproximam. Estabelecem-se traços mnêmicos propiciados pelo deslocamento catexico e guardados pela criança, que consegue diferenciar e reconhecer a mãe entre outros sujeitos, marcando o estabelecimento do primeiro objeto libidinal: o objeto de amor.

Esta fase é marcada pelo surgimento do segundo organizador da psique, que também está incluso nas mudanças fundamentais. Spitz atenta para a relação de interdependência das fases do desenvolvimento, apesar de serem aspectos diferentes da personalidade; a cristalização das respostas afetivas leva à integração do ego, cuja função influenciará no estabelecimento das relações objetais.

Ao passar dos meses, o ego vai se tornando cada vez mais influente e chega ao ponto de integrar os traços de memória de inúmeras e repetidas experiências e de trocas que a criança teve com a mãe. Tal relação ocorre aos seis meses e marca o aparecimento do objeto libidinal propriamente dito: a mãe única. Logo, a diferenciação é expressa em termos do sistema de memória egoica: quanto mais a experiência de troca é vivenciada, mais traços de memória são estabelecidos, facilitando para o bebê diferenciar a mãe, objeto que proporciona satisfação e desprazer, dos demais sujeitos. Spitz aponta também que este processo proporciona o aumento da capacidade de retenção da memória, cuja ampliação, após o sexto mês de vida, proporciona que os múltiplos perceptos que caracterizam o papel materno se unifiquem como um objeto libidinal.

Este período antecipa o estabelecimento do reconhecimento: a mãe se diferencia dos demais objetos do mundo externo, porém ela não é vista como indivíduo autônomo, e a ela serão direcionadas as pulsões libidinais e a agressivas, tornando o objeto bom e mau em um só objeto. Porém o objeto de amor prevalecerá na relação, o que leva a mãe a ser o objeto de amor.

Dentro desse contexto, há uma mudança significativa e que marcará o surgimento do terceiro organizador da psique. Antes os afetos eram expressos por meio do contato imediato; agora o diálogo e a troca de afetos expandem-se além do contato e passam a ser realizados por mensagens gestuais, dando origem à comunicação à distância. O "não" indica o estabelecimento do terceiro organizador da psique

Segundo Spitz, todo "não" da mãe é uma representação de uma frustração emocional, sendo que em todas as proibições, os gestos e as palavras impõem a frustração, investidos de uma carga afetiva que tem o significado de recusa. É importante salientar que as proibições à criança ocorrem no período em que a mesma está saindo do estado de passividade, um período de intensa mudança. Os impedimentos da ação da criança em direção a desejos e necessidades levam a um retorno ao estado de passividade. Em contrapartida, a criança oferecerá resistência a estas proibições que causam desprazer.

A criança vive a dicotomia entre agredir e amar o objeto libidinal. Tal acontecimento marca o início do reconhecimento: surgem as tensões entre autoabandono simbiótico e a autoafirmação individual. Tais informações se alinham com as informações sobre o reconhecimento, quando Honneth (2003) aborda a desilusão e a necessidade da mãe voltar parar as suas outras relações, gerando atos agressivos da criança. Com o tempo, ao perceber que há objetos para além da mãe, o bebê começa a ter a mãe como um ser dotado de 
autonomia, que não está estritamente ligado ao seu ser e, dessa forma, o reconhecimento é estabelecido.

\section{CONCLUSÕES}

A partir dos estudos realizados em Spitz, torna-se evidente que são imprescindíveis as interações sociais no primeiro ano de vida, considerando que as relações primárias estão na primeira esfera do reconhecimento e são consideradas moldes para as futuras relações sociais da criança. São elas que ditam o ritmo do desenvolvimento humano e influenciam diretamente na construção da percepção da criança, as quais surgem através de um processo de aprendizagem na díade mãe e filho. Toda a rede de cuidados, ações que visam sanar as necessidades e proteger a criança, e que ao mesmo tempo servem para satisfazer a carência afetiva; toda a comunicação que ocorre do bebê com o objeto de amor serve como base do seu desenvolvimento psíquico e físico.

Considerando que o reconhecimento ocorre em um contexto dialógico e de constantes trocas de afetos, a díade mãe e filho, abordada por Spitz, complementa o trabalho elaborado por Honneth para embasar a teoria do reconhecimento. Os organizadores da psique marcam os períodos em que o objeto está sendo estabelecido e, junto com os comportamentos mais complexos, o ego é estruturado e promove um maior controle da criança em relação a seu corpo e a busca pelas suas necessidades, ou seja, a saída do estado de passividade para ações ativas e com alvos específicos.

\section{REFERÊNCIAS}

BUNCHAFFT, M. E. Habermas e Honneth: leitores de Mead. Sociologias [online]. 2014, vol.16, n.36, pp.144-179. Disponível em: $<$ http://dx.doi.org/10.1590/15174522016003611.〉>. Acesso em: <<22/05/2016〉>.

HONNETH, Axel. Luta por Reconhecimento: A Gramática Moral dos Conflitos Sociais. São Paulo: Editora 34, 2003.

. La sociedad del desprecio. Madrid: Trotta, 2011.

MORRIS, Charles. (Org.). Mente, self e sociedade. Aparecida, SP: Ideias \& Letras, 2010.

SPITZ, René. O primeiro ano de vida. 4. ed. São Paulo: Martins Fontes, 2013. 